\title{
AN UNUSUAL PRESENTATION OF LIVER LACERATION
}

Ravindra G. Devani, Shanta B. Patil, Veerabhadra R, Sharanabasappa Gubbi, Ankur Bhatia,

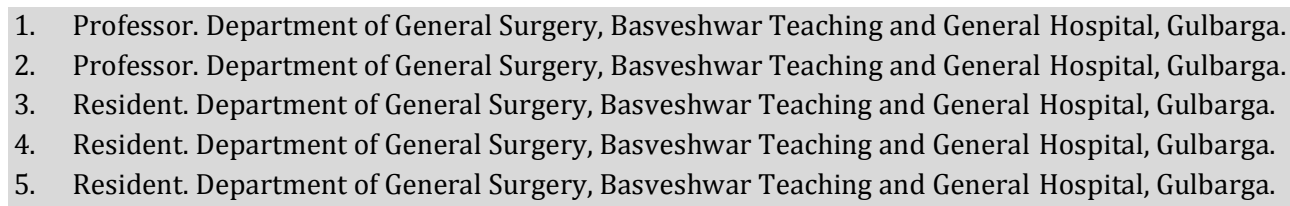

\section{CORRESPONDING AUTHOR:}

Ankur Bhatia,

Room Number 105, Men's Hostel,

BTGH, Gulbarga, Karnataka- 585105.

E-mail: docbhatia@gmail.com

ABSTRACT: Liver is the largest solid abdominal organ with a relatively fixed position, which makes it prone to injury. Liver trauma is the second most frequent event during an abdominal trauma and is the leading cause of death $(20-40 \%)$ in these cases. So it's a must to identify and treat liver trauma at the earliest for better outcome. A 22 year male was brought to casualty with history of road traffic accident. On examination, patient was drowsy but irritable with Glasgow Coma Scale (GCS) of13(E3+M6+V4). His abdominal examination was normal. Patient was admitted with the diagnosis of Traumatic brain injury and was put on treatment. After 48 hours of admission, patient became conscious and oriented with GCS of 15. He started complaining of pain abdomen. Abdominal examination revealed same findings as found at the time of presentation with additional positive shifting dullness. USG abdomen showed liver and splenic contusions with hemoperitoneum of $2000 \mathrm{ml}$. Patient was posted for exploratory laparotomy because of massive hemoperitoneum. A thorough abdominal examination revealed a destructed and devascularized hepatic segments II and III (Grade IV).

Physical examination of the abdomen is unreliable; drugs, alcohol and head and spinal cord injuries complicate clinical evaluation. Hence one should investigate for abdominal injuries especially liver trauma as Liver injuries present a serious risk for shock because the liver tissue is delicate and has a large blood supply and capacity.

INTRODUCTION: Trauma is recognised as a serious public health problem. In fact, it is the leading cause of death and disability in the first four decades of life and is the third most common cause of death overall. ${ }^{1}$

The liver is the largest solid abdominal organ with a relatively fixed position, which makes it prone to injury. Liver trauma is the second most frequent event during an abdominal trauma and is the leading cause of death $(20-40 \%)$ in these cases. ${ }^{2}$ So it's a must to identify and treat liver trauma at the earliest for better outcome.

We report a case of unusual presentation of liver injury presented to our institution.

CASE REPORT: A 22 year male was brought to casualty with history of road traffic accident. On examination, patient was drowsy but irritable. His Glasgow Coma Scale (GCS) was 13(E3+M6+V4). Pupils were bilaterally equal, normal in size and reacting to light. His Pulse rate was 72 beats per min, while blood pressure was 110/70 mm of Hg. His cardiac and respiratory 
examination was normal. Abdomen didn't have any external injury, there was no distension and was soft, non-tender, and bowel sounds were normal.

His haematological investigations were normal. CT scan of head revealed diffuse cerebral edema and fracture of left side of the frontal bone.

Patient was admitted with the diagnosis of Traumatic brain injury and was put on treatment.

After 48 hours of admission, patient became conscious and oriented with GCS of 15 . He started complaining of pain all over the abdomen. His vital examination was normal. Abdominal examination revealed same findings as at the time of presentation with additional positive shifting dullness.

Patient underwent Ultrasonogram of the abdomen and pelvis, which revealed contusions in the left lobe of liver measuring $3.8 \times 2.1 \mathrm{~cm}$ and mid pole of spleen measuring $4 \mathrm{x}$ $3.2 \mathrm{~cm}$; with free fluid of around $2000 \mathrm{ml}$. Patient didn't undergo CT abdomen as he wasn't affordable.

Patient was posted for exploratory laparotomy because of massive hemoperitoneum. A total of 2litres of bloody collection was suctioned. A thorough abdominal examination revealed a destructed and devascularized hepatic segments II and III (Grade IV). The segments were totally detached from rest of the liver, hanging by the partially intact left triangular ligament. The devascularized part of liver was excised. Haemostatic absorbable gelatin sponges were kept over raw surface of the liver. Rest of the liver was normal. Spleen had a contusion as described by USG. A peritoneal drain was placed and abdomen was closed in layers. Post-operative period was uneventful. Patient was discharged on $12^{\text {th }}$ post-operative day.

DISCUSSION: INTRODUCTION: Incidence of liver injury is on increase. ${ }^{3}$ The liver is frequently injured following abdominal trauma and associated injuries contribute significantly to mortality and morbidity, and may cause the liver injury to be masked and diagnosis delayed. ${ }^{4}$

Clinical examination: Liver injury should be suspected if there's any injury over the right and lower part of the chest, right hypochondrium and epigastrium. Bruise, laceration or perforating wound is the external sign of injury which one may locate on careful inspection and injury to internal organ may be at the depth of the external wound. ${ }^{5}$

Other signs include absence of abdominal movements because of peritonitis secondary to internal haemorrhage, localised or generalised distension and lower rib fractures. ${ }^{5}$

Isolated liver injury occurs in less than $50 \%$ of patients. In the literature, blunt liver trauma is associated with spleen injury in $45 \%$ of patients. ${ }^{6}$ The right lobe of liver is injured more commonly than the left. Most liver injuries (>85\%) involve segments VI, VII and VII.

INVESTIGATIONS: Jansen et al found that ten percent of polytrauma patients who had no clinical signs of abdominal injury did have evidence of such injuries using radiological imaging. ${ }^{7}$ Physical examination of the abdomen is unreliable; and drugs, alcohol and head and spinal cord injuries complicate clinical evaluation. ${ }^{8}$ Hence one should investigate for abdominal injuries especially liver trauma as Liver injuries present a serious risk for shock because the liver tissue is delicate and has a large blood supply and capacity. ${ }^{9}$

Investigations include Diagnostic peritoneal lavage, Ultra sonogram and CT scan. Diagnostic peritoneal lavage is helpful in unexplained shock, spinal cord injury and suspected abdominal injury in comatose, intoxicated or multiple injury patients. Ultrasound can detect 
fluid such as blood or gastrointestinal contents in the abdominal cavity ${ }^{8}$ and it is a noninvasive procedure and relatively safe for the patient. USG can find type of injury such as contusion or laceration and amount of injury. CT scan is the gold standard for the diagnosing parenchymal injuries and is also necessary for non-operative management of liver injury. Diagnostic laparoscopy or exploratory laparotomy may also be performed if other diagnostic methods do not yield conclusive results. ${ }^{10}$

TREATMENT: The management of liver trauma is mainly non-surgical. surgical literature confirms that as many as $86 \%$ of liver injuries have stopped bleeding by the time surgical exploration is performed, and $67 \%$ of operations performed for blunt abdominal trauma are non-therapeutic. ${ }^{6}$ Almost $80 \%$ of adults and $97 \%$ of children are treated nonsurgically by using careful followup imaging studies. ${ }^{6}$

Surgery is required only in the presence of other organ injury, increasing instability or failure of non-operative management. The management of liver injuries can be summarized as "the four Ps": Push, Pringle, Plug and Pack. At laparotomy, bleeding can be controlled by direct compression (push). The inflow from the portal triad is controlled by a Pringle's

man oeuvre, with direct compression of the portal triad. Any holes due to penetrating injury can be plugged directly. Finally, the liver can be definitively packed, restoring the anatomy as closely as possible. ${ }^{1}$

CONCLUSION: The liver is frequently injured following abdominal trauma and associated injuries contribute significantly to morbidity and mortality, and may cause the liver injury to be masked and diagnosis delayed. Physical examination of the abdomen is unreliable; and drugs, alcohol and head and spinal cord injuries complicate clinical evaluation. Hence one should investigate for abdominal injuries especially liver trauma as liver injuries present a serious risk for shock because the liver tissue is delicate and has a large blood supply and capacity. CT scan is the gold standard for diagnosing parenchymal injuries and is also necessary for non-operative management of liver injury. Diagnostic laparoscopy or exploratory laparotomy may also be performed if other diagnostic methods do not yield conclusive results.

\section{REFERENCES:}

1. Robert Handley and Peter V. Giannoudis: Introduction to Trauma. In Normal S. Williams et al: Bailey and Love's Short Practice of Surgery, 25th edition, Edward Arnold (Publishers) Ltd, an imprint of Hodder Education, London; pp 271-284. 2008

2. Gourgiotis S, Vougas V, Germanos S. Operative and non-operative management of blunt hepatic trauma in adults. J Heptobiliary Pancreatic Surg 2007; 14:387-91.

3. Al-Mulhim SA, Muhammad HA. Non-operative management of blunt hepatic injury in multiply injured adult patients. J R Coll Surg 2003; 4: 81-5.

4. Beal SL. Fetal hepatic hemorrhage: an unresolved problem in the management of complex liver injuries. J of Trauma. 1990; 30: 163-170.

5. Somen das: examination of abdominal injuries. In A Manual on clinical surgery, $6^{\text {th }}$ edition, pp: 331-336: 2004

6. Nawaz Khan A, Vadeyar H, MacDonald S and Chandramohan M. Liver Trauma. 2009; accessed online at: www.emedicine.com/radio/topic397.htm

7. Jansen JO, Yule SR, Loudon MA (April 2008). "Investigation of blunt abdominal trauma". BMJ 336 (7650): 938-42. 
8. C. Clay Cothren, Walter L. Biffl and Ernest E. Moore: "Trauma”. In F. Charles Brunicardi et al.: "Schwartz's Principles of Surgery", 9th edition, Mc Graw Hill Companies Inc., United states; pp 136-206, 2010.

9. Visrutaratna P, Na-Chiangmai W (April 2008). "Computed tomography of blunt abdominal trauma in children". Singapore Med J 49 (4): 352-8; quiz 359

10. Hemmila MR, Wahl WL (2005). "Management of the Injured Patient". In Doherty GM. Current Surgical Diagnosis and Treatment. McGraw-Hill Medical. pp. 227-228; 2008.

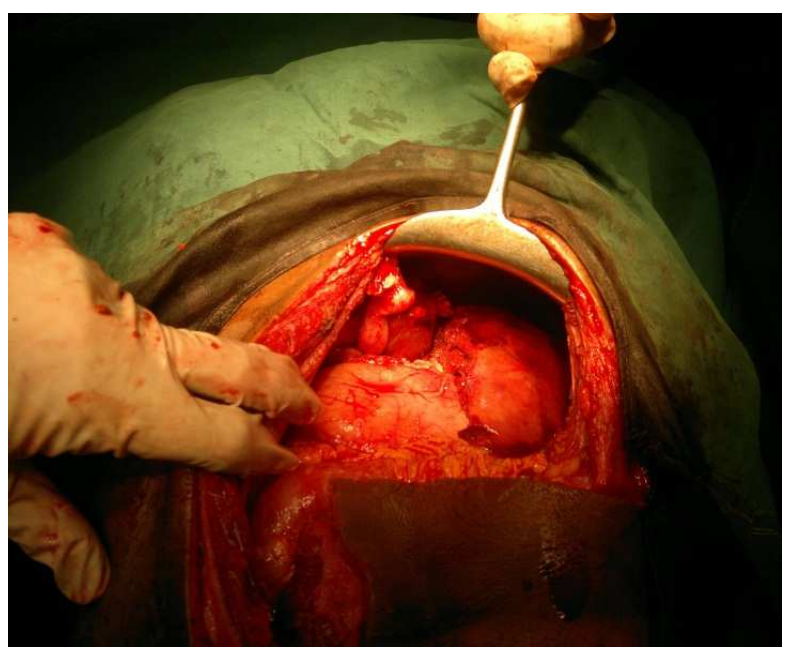

Fig 1: lacerated liver seen at laparotomy.

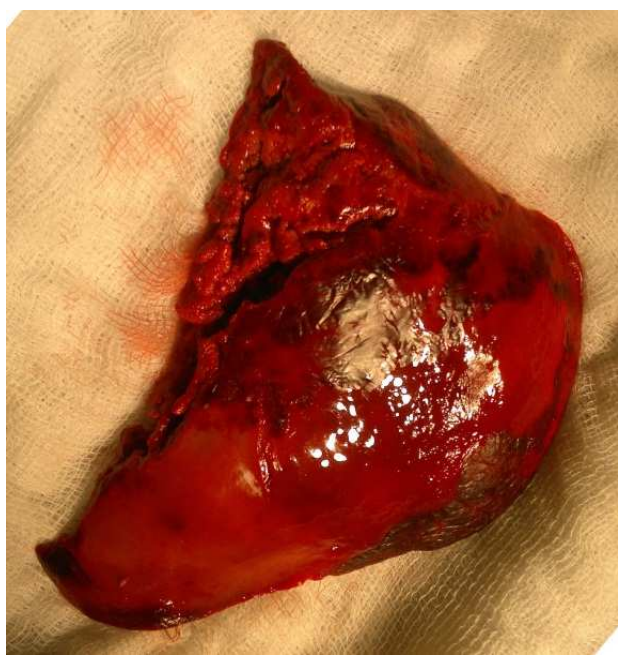

Fig 2: The excised part of liver.

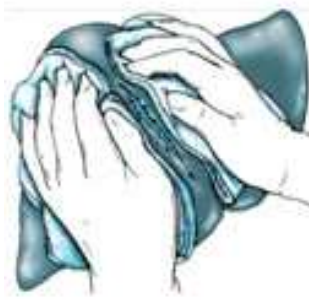

PUSH

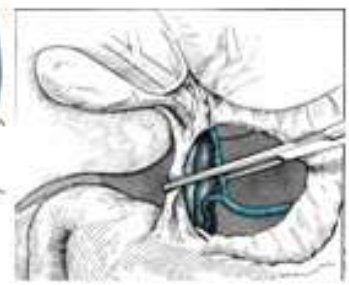

PRINGLE

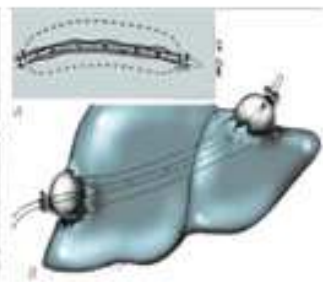

PLUG

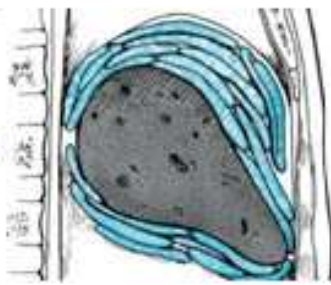

PACK

Fig 3. Management of liver trauma 